\title{
Os paclé (portugueses) em narrativas goesas de língua portuguesa ou o "mimetismo regrado"
}

\section{Everton V. MACHADO'}

Há um termo indo-português, com origem na língua natural de Goa, para designar o português: pacló (plural paclé, feminino paclina). Supõe-se que venha do vocábulo concani $p a k h$, "“pena' ou 'pluma', que teriam os militares nos seus chapéus ou bonés" (DALGADO, 1921, p. 128). Não deixa de ser curioso tal termo se ter forjado sob a evidência ela mesma da autoridade colonial, já que servia, inicialmente, para nomear os agentes repressores numa maior proximidade com a população, os soldados da

1 Investigador Auxiliar da Faculdade de Letras da Universidade de Lisboa. Vice-diretor do Centro de Estudos Comparatistas e coordenador do grupo de pesquisa "Orientalismo Português - séculos XIX e XX". Docente nos programas de mestrado e de doutoramento em Estudos Comparatistas, Língua e Cultura Portuguesa e Comunicação e Cultura. Desenvolve o projeto "The Portuguese Representations of India: Power and Knowledge in a Peripheral Orientalism (XIX and XX centuries)", financiado pela Fundação para a Ciência e a Tecnologia de Portugal (IF/01452/2013), com duração de cinco anos (2013-2018); evermachado@gmail.com 
Coroa Portuguesa. Mais tarde, veio também a ser aplicado aos membros das elites locais, pelo seu grau de aproximação à cultura ocidental. Fala-se até em paclocultura, como recorda Maria Aurora Couto:

O resultado das políticas coloniais para erradicar a cultura e a língua materna tradicionais é bastante evidente: nas castas altas, os que trabalhavam dentro do sistema mudaram muito mais do que os que trabalhavam na terra, a menos que se tratasse de proprietários abastados. Como costumava dizer Raul Fernandes, professor de liceu e famoso humorista, a cultura de Panjim é a paclocultura, a cultura do homem branco. [...] Quanto à classe trabalhadora ou campesina, eram pessoas que viviam com a sua nova fé e tinham escolhido o que pretendiam e conseguiam preservar, sem dar muito nas vistas. Nunca aprenderam o português. Não tinham nada a perder nem a ganhar. (CouTo, 2012, p. 164-165)

Em textos escritos tanto por portugueses quanto por goeses, nota-se uma diferença de atitude destes para com os primeiros ou o que Portugal simboliza, diretamente relacionada com o tipo de aproximação que os locais mantinham com o poder colonial. No caso da classe campesina acima referida, o romance $O$ Signo da Ira (1960), de Orlando da Costa (1929-2006), sugere uma relação com os portugueses marcada sobretudo pelo medo. A narrativa aborda, já no século XX, a vida dos curumbins (agricultores) e um entorno que é o mesmo no qual terá surgido o termo pacló: o dos soldados portugueses. Não partilhando com as classes mais altas os costumes e a língua portugueses, apenas a religião cristã, essa classe sempre foi, de resto, mais permeável a práticas sociocultu- 
rais e religiosas oriundas do meio hindu, ${ }^{2}$ cuja visão dos paclé, por seu turno, e a julgar pelo que escreveu em finais do século XIX o agrónomo português António Lopes Mendes (1835-1894), não era diferente: "os gentios das Novas Conquistas 3 fugiam do pacló (europeu) como o diabo da cruz" (Mendes, 1886, p. 63). No caso das elites mimetizadas, beneficiárias do poder colonial e concorrendo para o bom funcionamento deste, o quadro é bem outro: os portugueses são objeto ou de fascínio ou de total desprezo. Para se compreender adequadamente as representações que daí derivam, faz-se necessário observar não apenas como os portugueses são retratados, mas também as próprias elites nativas, em articulação com a conjuntura sócio-histórica e política.

A representação dos paclé nas narrativas (conto e romance) da literatura chamada "indo-portuguesa" que aqui serão referidas confirmam, antes de mais, aquilo que a etnomusicóloga Susana Sardo, estudiosa da cultura de Goa, chamou de "mimetismo regrado", tal noção podendo ser utilizada na área dos Estudos Literários como grelha de leitura ou mesmo conceito operatório para se identificar com clareza as nuances dos discursos observados ou situá-los devidamente nos contextos que lhes são próprios. Escreve a especialista:

2 "O apego aos costumes é mais forte nas castas baixas, muito menos tocadas pela influência portuguesa e mais próximas da tradição hindu” (Thomaz, 1994, p. 274). Vejam-se os romances Bodki (1962), de Agostinho Fernandes, e O Último Olhar de Manú Miranda (2000), de Orlando da Costa, que abordam crenças e costumes originados a partir de cultos primitivos locais.

3 Chamadas desta forma as terras conquistadas pelos portugueses em Goa apenas em finais do século XVIII (Perném, Bicholim, Satari, Pondá, Sanguém, Quepém e Canácona), por oposição às "Velhas Conquistas" do século XVI (as "ilhas" de Goa e as províncias de Bardez e Salcete). 
[...] perante um quadro que apresenta por um lado uma organização política constituída por uma população flutuante de portugueses, minoritária, da qual dependem as decisões políticas, administrativas e militares de Goa e, por outro, uma população fixa, maioritária, profundamente organizada e hierarquizada, de consolidadas relações internas de poder, da qual depende o equilíbrio social e cultural da população católica e hindu de Goa, parece claro que a fragilidade natural do poder colonial só poderá ter sido superada através da cumplicidade de uma elite local que entretanto se sedimentou e cujo interesse de manutenção provinha das duas esferas de influência: a portuguesa e a goesa. Podemos dizer que se trata de uma elite que se enquadra claramente no conceito de mimetismo proposto pela teoria do pós-colonialismo. Porém, no caso dos goeses, trata-se de um mimetismo regrado, um mimetismo instigado pelos portugueses, aceite pelos goeses mas controlado por ambos. A proximidade com os estereótipos de portugalidade, propostos pelos portugueses com as regras a que a postura colonial obrigava - suficientemente portugueses, mas sem deixarem de ser indianos - era também controlada pelos goeses, ou seja, a proximidade com os portugueses era conveniente, tinha algumas vantagens sob o ponto de vista económico e social, mas não deveria ultrapassar algumas fronteiras que pusessem em causa a própria goanidade. (SARDO, 2011, p. 118; ênfase minha)

Ao contrário do primeiro romance de língua portuguesa de Goa, as narrativas seguintes trarão ao de cima as ambiguidades 
geradas no âmbito desse mimetismo. Em Retrato do Colonizado, publicado originalmente em finais da década de 1950 e referindo a esfera colonial francesa, Albert Memmi já tinha afirmado que "é este o drama do homem-produto e vítima da colonização: ele quase nunca consegue coincidir consigo mesmo" (2007, p. 181).

Em Os Brahamanes (1866), de Francisco Luís Gomes (1829-1969), para além de a trama do romance se desenrolar no norte da Índia, controlada pelos ingleses (nas narrativas posteriores, Goa será sempre o cenário privilegiado), o português surge-nos com uma espécie de natureza arquétipa, através da figura do missionário Frei Francisco de Santa Catarina, modelo de virtudes liberais e cristãs, exemplo de conduta para o Império britânico (Machado, 2012). Com a construção, ao longo do tempo, da goanidade, ou o que Ângela Barreto Xavier apontou como sendo a invenção de Goa, "as elites de origem local, [...] deixaram de se rever, de certa forma, no estatuto de colonizados", havendo ocorrido uma "transfiguração imaginária do colonizado em colonizador" (2008, p. 26). Repare-se que Francisco Luís Gomes foi até deputado por Goa no Parlamento português, em Lisboa, sendo fulcral para os argumentos que tece na sua obra o direito outorgado aos goeses católicos de acesso à cidadania portugue$\mathrm{sa}^{4}$ o que não acontecia com os indianos sob o jugo britânico. $\mathrm{O}$ romancista fazia parte de uma geração ainda de goeses diretamente exposta, como lembra por sua vez Maria Aurora Couto,

4 Como conta Sandra Ataíde Lobo: "durante a Monarquia Constitucional, a comunidade religiosa se estabeleceu como medida primordial da integração do nativo católico no conceito de cidadão português. Significando esta afirmação que neste discurso é recorrente a ideia de cidadão nativo católico como contemporâneo do cidadão metropolitano e por isso mesmo com autoridade para reivindicar o pleno usufruto dos seus direitos [...]" (2013, p. 112). 
[...] to the ideals of the French Revolution, the Enlightenment and aspirations born with the new Constitution of 1823 created an efflorescence in Goa. It produced a Goan sense of self and an elite society galvanized by its own concerns. [...] They built up collections in their bibliothecas, poured over classics and the work of great minds. They broadened it with Liberalism, learnt to question and to dare with the Encyclopaedists. (CouTO, 2007, p. 88-89)

Noutro romance, vindo a lume após um hiato de trinta anos, são personagens locais que são sobretudo retratadas através da sua adesão à paclocultura. Os reinóis (também soldados, mas ver-se-á que sem o estigma da ameaça, bem pelo contrário) não escapam à língua viperina do autor: percebe-se também um hiato na representação dos portugueses.

Em Jacob e Dulce - scenas da vida indiana (1896/1974), de Francisco João da Costa, estamos diante de uma sátira à dependência da burguesia média católica de Goa a hábitos ocidentais. O contexto sócio-histórico aquando do aparecimento dessa narrativa era bastante oportuno: a seguir à "luta surda entre a elite cristã local e a nobreza crioula" (esta última formada pelos descendentes dos portugueses) que veio atravessando o século, a primeira já tinha começado a dominar "a vida pública do território, [ocupando] a quase totalidade dos quadros, exceção feita aos postos-chaves de governador, de patriarca e de presidente da Relação, sempre reservados a europeus" (THOMAz, 1994, p. 264-267). Vejamos três exemplos de como a referida burguesia nos é apresentada em Jacob e Dulce: 
Aos 22 anos Jacob encetara o estudo de direito.

Era um mancebo guapo, um pouco trapalhão, acanhado diante de senhoras, meticuloso na questão de vestuário. Pouco lhe importava a limpeza do seu corpo, queria as calças à moda em vigor na cidade.

Afligia-se quando o casaco não tivesse o número de botões que marcavam os janotas conceituados e autorizados.

Para ele, o europeu que deparasse na rua, era a personificação da moda, embora o seu fato tivesse sido talhado, no século passado, em Banana.

Para cada vestuário tinha andar especial.

Com simples casaco, movia-se como fadista, mãos em leque impedindo a queda imaginária de punhos imaginários, chapéu à banda, gravata em desordem.

De sobrecasaca ninguém seria capaz de fazê-lo caminhar apressado. Ia pausado, imitando o juiz de direito ou o administrador do concelho, e, como eles, esperava que o saudassem primeiro, e a todos os que o cumprimentavam, retribuía galhardamente com um sorriso de proteção. (Costa, 1974, p. 7)

Nos fins de dezembro, dona Sabina, viúva, mãe da menina Tertuliana e irmã de Salvador Pereira, pediu a este que mandasse a Dulce passar alguns dias consigo.

Era o porcondo ou procondio.

Ignoro a origem do porcondo, e o que propriamente significa. Quando recorri ao dicionário português, só encontrei: porco s. m. quadrúpede. Disse.

Salvador desculpou-se cortesmente alegando incómodos da esposa e lições de piano de Dulce. 
Mas dona Dorotêa e os Dantas acoimaram a recusa de fonice. Diziam eles que Tertuliana estava para casar em maio, a quem também Salvador teria de convidar para sua casa como tio, o que importava despesas, que ele queria evitar.

Contudo dona Sabina tanto insistiu, tanto rogou, tantas vezes alegou a sua qualidade de tia da noiva, que Dulce obteve permissão para ir à casa da mãe de Tertuliana. O porcondo moderno é uma sensaboria. Europeanisou-se. Por via de regra, dá-se uma soirée como qualquer outra, onde a noiva vem e vai com os convivas. Um advogado, célebre pela sua eloquência nas polícias correcionais, faz o brinde da noiva, em que fala do noivo, e diz deste tudo o que não é.

A única coisa que há aí de notável, é a atitude da noiva, que se requebra demais, toma uma desenvoltura imprevista e inesperada, e para ser considerada menina desembaraçada quer responder a tudo e diz disparates, quer ser chistosa e torna-se pedante, assim como acha graça a tudo o que diz o noivo. (Costa, 1974, p. 9)

- É verdade, ainda há bocado, haverá um par de horas, quando o astro do dia ia banhar-se no oceano, deixando após...

- Está poético o amigo, atalhava Miguelinho.... Estimo ouvir-lhe falar com esse rendilhado de frases e com estilo tão facetado...

- É o meu feitio, que diz Celestino? À força de leitura de livros literários, adquiri essa maneira de falar, que é-me natural e de que até um europeu se admirou...

- Eu noto também isso em mim, interrompeu Casimiro, 
quando leio o Camilo; caem-me involuntariamente frases dos lábios, como gotas de orvalho em uma manhã de inverno.

- Não gosto tanto de Camilo Castelo, não escreve mal, é certo, sustentou Celestino com ar superior; algumas páginas que eu perlustrei; ainda ontem estendido no meu divã... não me desagradaram.

- O meu fraco é Júlio, fez Miguelinho.

- Que Júlio? inquiriu Casimiro.

- Júlio Dinis...

- Não é mau... Vi as Pupilas.

Estes três pelintras estavam na mesma tarde na igreja, de chinelos, vendo o casamento de Jacob, e na véspera furtando goiabas no quintal da casa paroquial, donde foram corridos pelo cozinheiro do pároco, deixando um deles no sítio os seus chinelos. (Costa, 1974, p. 106)

A crítica tem visto nessa obra de Francisco João da Costa um certo rechaço à cultura ou aos valores portugueses e, por conseguinte, uma defesa dos costumes locais ou de uma ideia de "indianidade", mas o discurso do autor não deixa de ser complexo. Tal como as suas personagens, Francisco João da Costa pertencia ao universo da paclocultura e o narrador de Jacob e Dulce não se mostrava ele próprio disposto a abandonar certas atitudes do seu meio, como se pode ver a seguir. Repare-se ainda que é o "índio" aquele que vem a ser sobretudo percepcionado como o Outro por um narrador também nativo do território:

[...] é indubitável que a Índia Portuguesa é a pátria do langotim [tanga]: os vestuários ocidentais dificilmente se aclimam aqui, ou se fazem necessários. 
O índio usa deles por convenção, sem nenhuma necessidade; e secretamente os odeia.

Coloque-se o índio, por mais graúdo que seja, por mais civilizado à europeia, independente dos respeitos humanos, fora do alcance dos comentários do vizinho, ele sucessivamente prescinde do casaco, da camisa, das calças, e passa a habitar na cabaia.

Da cabaia para o langotim não vai um passo.

É atavismo francamente acusado.

Tenho observado isto até no índio educado na Europa. Quando regressa a pátria, nos primeiros tempos, dir-se-ia que não pode separar-se das botas, peúgas e gravata. Pouco a pouco S. Excelência esquece-se de vestir estes objectos. Depois chega a vez do casaco e de outras roupas. Deixem-no longe dos comentos, e vão buscá-lo no fim de 4 anos.

Recebe-os de langotim e pedra verde! É atavismo.

Se eu observei os mesmos fenómenos comigo!

Estive uma vez no fundo das Novas Conquistas, no meio de uma povoação vestida de langotim e sem receio de ser surpreendido pelo índio civilizado à europeia e de calções. Ao cabo de uma semana, estava todo dia de ceroulas e camisola, e passei assim o mês inteiro.

Se não enfiei o langotim, não foi por falta de vontade, mas sim pelo medo de que me confundisse com os habitantes da localidade, e pelo receio de que os manducares [cultivadores] me tratassem por: Agá bauddi! [pessoa tosca] Já vi a influência do meio nos europeus reinóis. Tenho-os encontrado de langotim; eram soldados reformados que se deixaram ficar na Índia. 
Deparei outros de robe de chambre sobre o corpo nu: estavam no grau de cabaia. Havia 6 anos que se achavam na Índia; eram magistrados judiciais. Se estes senhores demorassem mais 10 anos no país, suponho que presidiriam as audiências de langotim com cinto de prata. Dantes, os governadores-gerais podiam estar na Índia, como tais 5 anos. Este tempo foi reduzido a 3 anos. Algum ministro, previdente, receou talvez que o general presidisse ao conselho do governo... de langotim, com cinto de ouro, pedra verde com volta de corais, além de lenço vermelho de Damão envolvido à cabeça. (Costa, 1974, p. 47-49)

Ao narrador não lhe cairia bem o vestuário nativo, por gozar de um estatuto social, enquanto católico das elites e aportuguesado, que o regime colonial proporcionava. O que parece estar, realmente, sob a mira das suas admoestações ao longo de Jacob e Dulce é o simples "macaquear" da cultura ocidental, a superficial assimilação por goeses católicos dos ingredientes da portugalidade. Na altura em que escrevia Jacob e Dulce, estimulava-se a ocidentalização "por via da educação e da apropriação dos costumes da modernidade europeia", em especial entre as mulheres das elites, que deviam corresponder a "um modelo de feminilidade" (LoBO, 2013, p. 50), e, na obra, Francisco João da Costa visava também, através da formação dada à personagem Dulce (para se casar), essa educação. Como defende Sandra Ataíde Lobo:

Ao remeter a necessidade de ostentar o domínio do português, da leitura e da escrita e as prendas musicais, como valorativos da mulher no mercado do casamento, 
GIP $^{5}$ omitia o suporte deste modelo, para melhor evidenciar a superficialidade da sua assimilação. Omitia o lugar que no quadro do conceito burguês de família enquanto suporte da moderna sociedade patriarcal vinha sendo preconizado para a mulher, sustentado o seu papel na organização da casa e na reprodução social de valores e padrões comportamentais. É neste âmbito que ganha consistência o discurso em prol da instrução feminina, vista como fundamental à aprendizagem do papel de educadora, de organizadora da economia doméstica e de zeladora do bem-estar da sociedade familiar. [...]. Nesse sentido, a denúncia de GIP aplicava-se ao parcial falhanço desse projecto, quando transformado em convenção social, sedimentada por práticas miméticas das elites subalternas. (2013, p. 52)

Se, por um lado, o autor pareceria, no fundo, não abrir mão da paclocultura, por outro, o que Susana Sardo chamava acima de "mimetismo regrado" reflete-se, no último excerto de Jacob e Dulce reproduzido, na ironia com que fala dos europeus reinóis. O próprio pacló é objeto de uma atitude eurocêntrica, numa clara inversão de papéis, já que se orientaliza, ao adoptar costumes indianos. Não será despiciendo perguntar-se se Francisco João da Costa não estaria ali a tirar partido do largo processo de subalternização dos portugueses por parte dos países europeus hegemónicos, pelo que se considerava ser a cafrealização (adoção dos costumes dos povos tidos por primitivos e selvagens) dos primeiros (SANTOS, 2001, p. 46-64), bastante em sintonia com a

5 Pseudônimo com que Francisco João da Costa publicou Jacob e Dulce - scenas da vida indiana. 
"lenda negra" construída em torno do Império português, associando a procura de indianização ou nativização por algum estrato de lusitanos "à ideia de que os portugueses eram incapazes de se governarem a si mesmos (i. e., de controlarem as suas paixões, de autodisciplinarem a sua natureza) e, por conseguinte, de governarem os outros" (XAvier, 2014, p. 112). O período de Francisco João da Costa é marcado por muitas críticas à administração portuguesa e por uma vontade de autodeterminação. Assim, tal excerto de Jacob e Dulce poderia ilustrar muito bem o que Boaventura de Sousa Santos caracteriza como "espaço de manobra adicional" para o colonizado "tentar a sua auto-representação para além ou fora da representação da sua subalternidade" (2001, p. 27), em virtude, justamente, da possibilidade aberta pelo caráter subalterno ou semiperiférico do colonialismo português face à "norma geral" (p. 26) de colonialismo representada pelo Império britânico e à própria dependência de Portugal à Inglaterra. De qualquer modo, numa certa goanidade - e não "indianidade", por uma elite acabar por preterir costumes locais em vista da sua "Ilustração" (rever Couto acima) - não entram certas atitudes, mesmo se em prática entre os portugueses.

Noutro autor goês de língua portuguesa, José da Silva Coelho (1889-1944), tido pelo herdeiro de Francisco João da Costa, há portugueses e portugueses. Num conto como "O Monserrate", o "mimetismo regrado" declina-se de uma maneira distinta, segundo a própria ação no interior da narrativa: através de um jogo especular entre a burguesia ilustrada e os reinóis, fazendo variar a imagem dos lusitanos consoante a posição destes na sociedade. Um bom português para o protagonista (Bonifácio Monserrate) era aquele cujo estatuto poderia corresponder ao 
seu, o de profissional liberal, ${ }^{6}$ abolindo-se assim, pelo menos ao nível do imaginário (como Ângela Barreto Xavier sugeriu antes quanto à generalidade das elites), a fronteira entre colonizado e colonizador. Um bom português devia ser o seu igual. Esse não era o caso, definitivamente, dos soldados. Vítima da ironia de José da Silva Coelho, tal como ocorre na obra de Francisco João da Costa, a superficialidade das convenções do meio de Goa de que o primeiro também fazia parte ${ }^{7}$. Vejamos o que nos diz o narrador de "O Monserrate":

A outra paixão do Bonifácio eram os bacharéis de Direito pela Universidade de Coimbra. Não os indianos formados na Metrópole - por estes nutria uma secreta inveja e tinha-lhes raiva -, mas os bacharéis europeus. E, ampliando a sua paixão, começou a adorar todos os europeus civis, porque aos militares, embora oficiais de engenharia, taxava-os de tarimbeiros e não lhes ligava importância. E não passava europeu algum à paisana, conhecido ou desconhecido, sem que o Bonifácio Monserrate o cumprimentasse logo, com rasgadas barretadas, e procurasse por todos os meios aproximar-se dele e ser-lhe agradável.

Ora, sucedeu que Cipriano Cantina, soldado de infantaria europeia, que estava em diligência nas Obras Pú-

6 Segundo Thomaz (1994, p. 268): "a élite goesa revelou sempre uma grande predilecção pelas profissões liberais, particularmente as de médico e advogado". Estas profissões gozavam de bastante status, revelando-se aí, provavelmente, a mesma "influência do $b a$ charelismo que na mesma época era dominante em Portugal como no Brasil, países pouco atingidos pela revolução industrial e portanto sem uma verdadeira burguesia capaz de substituir os seus valores pelos da pseudo-burguesia de letrados (saída, em grande parte, dos proprietários fundiários) que implantara o liberalismo e dominava a cena política". 7 Compare-se, aliás, o primeiro excerto reproduzido do segundo autor com os do primeiro a seguir, no que diz respeito aos sinais exteriores e às profissões. 
blicas, andasse à paisana enquanto olhava pelos consertos que se estavam fazendo na aldeia de Bonifácio. Este, apesar de o Cantina estar muito queimado pelo sol e mais escuro que um cantoneiro, conheceu pela fala que era europeu e, supondo-o civil, imaginou-o logo engenheiro. Daí a fazê-lo bacharel em Matemática não ia um passo, e logo o Bonifácio começou a fazer rasgados cumprimentos ao passar e repassar por Cipriano Cantina, que este ficou muito admirado de uma tão subida consideração por parte de um ilustre advogado. (Coelho, 1979, p. 159-160)

Posteriormente, foram ambos convidados a uma soirée de casamento. Cipriano Cantina, incomodado com a "sobrecasaca velhíssima" que arranjara, hesitava em entrar na casa onde decorria o serão. Bonifácio Monserrate, depois de se dar conta, pela janela, da chegada do primeiro, vai ter com ele à rua. Cantina pede a Monserrate a casaca deste por uns instantes, o tempo apenas de ir cumprimentar os noivos, para não passar por um indelicado. O goês acede ao pedido, mas o português, entusiasmado com a namorada que lá encontra, fica a dançar durante a noite toda, deixando a casa só de madrugada. Nesse ínterim, Monserrate

[... pela primeira vez duvidou da autenticidade do bacharel em Matemática e, como a noite esfriava, envergou a sobrecasaca do Cipriano Cantina que até então trouxera, respeitosamente, no braço. Mas, sentindo o cheiro a bafio e a coisas velhas a que tresandava a velhíssima sobrecasaca, percebeu o logro em que caíra: nunca uma pessoa que trazia uma sobrecasaca daquelas podia ser bacharel. [...] 
Hoje, quando vê um europeu, não o cumprimenta logo, nem mesmo de longe, com uma rasgada barretada: espera, prudentemente, que se aproxime, e depois de minuciosamente o observar, faz-lhe um vagaroso e respeitoso cumprimento. (Coelho, 1979, p. 161)

Na ficção goesa de língua portuguesa passada a integração de Goa na União Indiana em 1961, é através ainda das elites mimetizadas, mas também de setores marginalizados da população, que a percepção dos paclé pelos goeses nos é sugerida.

No conto "A subvenção", da coletânea Monção (1963), Vimala Devi (nascida em 1936 e vivendo há muitas décadas em Barcelona) fustiga certas idiossincrasias dos descendentes de portugueses, na primeira metade do século XX. Por causa de uma subvenção colonial que lhes vem a ser oferecida, Eucaristino, um oficial da Fazenda, entra em casa de forma diferente dos outros dias, a gritar para a mulher e os filhos que daí em diante tudo iria mudar, os utensílios domésticos seriam substituídos por aparelhos ocidentais, as apas (bolo de farinha assado em barro) por pães e o caril por bacalhau, já que agora eram considerados paclé: "nós agora somos civilizados, não somos como goeses" (Devi, 2003, p. 125). No romance O último olhar de Manú Miranda (2000), de Orlando da Costa (instalado em Portugal desde os 18 anos de idade e lá falecido), Ubaldino Antão, da elite autóctone, revolta-se com "a obsessão de uma camada culta da sociedade querer exibir a sua erudição e enaltecer, no seio das suas próprias famílias, figuras da cultura europeia”, para finalmente concluir com desgosto serem os goeses "uma espécie de macacos de imitação", uma prova disto residindo no "costume de uns quantos 
brâmanes ${ }^{8}$, que na ânsia de demonstrar a sua familiaridade com tudo quanto fosse europeu, consultavam em almanaques franceses nomes sonantes para de entre eles escolherem os que mais lhes agradavam" (Costa, 2000, p. 248). Em Casa Grande e outras recordações de um velho goês (2008), de Leopoldo da Rocha (nascido em 1932), a mãe de Bal, o protagonista, é marcada pela "mania de ostentação balofa do estilo português, embora ela, em família e entre os seus membros, falasse só o concani” (RochA, 2008, p. 86). Mais: "detestava tudo que não fosse do figurino colonial" (RochA, 2008, p. 86). O português é o modelo a seguir a qualquer custo para muitas personagens, enquanto outras e mesmos os narradores não são nada simpáticos para com os portugueses: veja-se ainda a narrativa de Leopoldo da Rocha, na qual, apesar de "pessoa inapta", o "director espiritual" do seminário por onde passara o protagonista era "o único português europeu de confiança do estado" (2008, p. 124). Na fase pós-colonial, no entanto, já não se trata mais para os escritores de controlar "os estereótipos da portugalidade" (cf. SARDO, 2011, no início): compreende-se que é a própria ideia de goanidade que é controlada, pela consciência dos autores quanto às ambiguidades que encerra e à difícil síntese a que se procura chegar. A distância para com a realidade objetiva da presença colonial em Goa o terá, sem dúvida, estimulado.

Se, em Jacob e Dulce, de Francisco João da Costa, no período oitocentista, era sinal de prestígio para as moças das elites dançar com os paclé, no conto novecentista "Esperança", de Vimala Devi, também incluído em Monção, algo semelhante significava uma ignomínia. Conta-nos o primeiro:

8 A casta mais alta no sistema hierárquico-social da Índia, tanto na esfera hindu como católica. 
D. Tatarícia queria que a filha sobrelevasse a todas as donzelas da cidade de Breda, e quando, na igreja, por ocasião do recebimento, viu a toilette pomposa de Tertuliana, perdeu a cabeça. Seria um escândalo que sua filha, que era da capital, que assistira às soirées do club, que uma vez dançou com um guarda-marinha europeu, e duas vezes com o capitão do porto (europeu) e mais uma vez com um alferes (europeu), fosse vencida por uma provinciana, que nunca dançou com um europeu!... (Costa, 1974, p. 112)

No segundo, as jovens goesas, se andassem "a dançar com os paclé", seriam mal faladas, tratadas por "malucas" (DEvi, 2003, p. 62.). Roberto é cioso da reputação das irmãs:

"Só não gosto nada que vocês dancem com os paclé. Porque não dançam só com os nossos rapazes? Os paclé não têm moral e dão mau nome às raparigas, sabes bem!" "Nisso tens razão", respondeu Mitzi, muito séria. "Nossos rapazes são tão diferentes dos paclé. Tu achas-me capaz de casar com um deles? Além disso, eles aqui fazem figura, mas quando estão na Europa são uns pelintras. E estúpidos, não reparaste ainda? Nossos rapazes são muito diferentes e quando casam é para toda a vida. Eles mudam de mulher como quem muda de camisa... Preferia casar com um sudra ${ }^{9}$ do que com um pacló! (Devi, 2003, p. 63-64)

9 A casta mais baixa, tanto na esfera hindu como católica. 
No que concerne à paclina (portuguesa), a aversão, em certos casos, podia ser a mesma, e não só na comunidade católica, mas também na comunidade hindu. No seu trabalho de campo, inclusive, o geógrafo português Orlando Ribeiro tinha reparado o que "dizem as mães goesas: 'Casou com uma paclina (=europeia) já está o meu filho perdido"' (RIBEIRO, 1999, p. 79-80). Em "Fidelidade", outro conto de Vimala Devi, um hindu que fora para Portugal tirar o curso universitário e deixara a mulher na Índia, envolve-se sexualmente com uma portuguesa, retratada pela autora como sobejamente frívola, desprezando tudo quanto diz respeito aos costumes da família do amante e incorrendo numa sistemática infantilização desse Outro oriental que quer manter como companheiro (Devi, 2003, p. 87-90). No romance O último olhar de Manú Miranda, se, por um lado, nascer com a pele clara das paclinas, é sinal de beleza e granjeia status social às goesas, por outro, consoante a situação e o meio, estas podem passar a vida sendo apodadas de paclinas não por respeito e admiração, mas por pura troça. Imagine-se, então, o caso das descendentes dos portugueses, como Martha Catarina, "mulher não [...] indicada" (Costa, 2000, p. 125) para Emílio, membro de uma das elites autóctones.

Noutro romance de Orlando da Costa, O Signo da Ira, mencionado na introdução, os portugueses são mesmo os soldados, na sua maioria. A classe agrícola dos curumbins é explorada tanto pelos paclé quanto por uma das elites locais, os batcarás, donos de terras, sendo os curumbins os seus manducares, cultivadores. É ali posta em cena a permanente tensão entre esses desvalidos da sorte e os soldados expedicionários portugueses, considerados maus e tidos até por violadores, uns "malditos demónios", verdadeiros "inimigo[s]" (Costa, 1996, p. 16 e 19). 
- Sabe, avô... - o seu olhar desviou-se, deixando suspenso um véu de malícia e ingenuidade. - No outro dia esteve aqui um pacló, um desses soldados que agora passam pela estrada...

- O quê? - admirou-se Jaqui. - Onde? Aqui?

- Sim, aqui mesmo, no povoado. Eu estava junto do poço e ele aproximou-se... [...]

- E o que queria ele? - a voz do velho erguia-se trémula sob o peso da ansiedade. Não ouvira já ele histórias estranhas e terríveis sobre esses homens? Talvez fossem inventadas, talvez simples mentiras, mas ele estava com medo, com medo, porque acreditava nelas. - E o que queria? - Água... - respondeu a rapariga. - Tirou-me o calão da cabeça... e bebeu. E eu fugi, cheia de medo. [...]

- Não quero que você lhe apareça mais, ouviu? - berrou Jaqui, erguendo a mão numa ameaça. Natél compreendeu que aquela mão se erguia não contra ela, mas contra o estranho de quem ele acabara de ouvir falar. - Lá porque é soldado julgará que tudo isto é seu?... - na sua voz irritada a raiva abriu um sulco. E Natél estremeceu. (CosTa, 1996, p. 54-55)

Para esta classe, ao contrário das outras, os portugueses seriam realmente "gente estrangeira, não são como nós" (CosTA, 1996, p. 28; ênfase minha). No caso das elites, das quais saíram os próprios escritores aqui abordados, estas são e não são como os portugueses, enredadas para todo o sempre na teia da paclocultura. Uma afirmação acerca dessa condição por parte de outro escritor saído também desse estrato social (mas autor de língua inglesa), João da Veiga Coutinho, constituiria um axioma perfeito do 
"mimetismo regrado". Afirma, pela boca do Padre Gabriel Saldanha (1853-1930), que escreveu uma História de Goa (1925/1926) e com quem imagina uma conversa: "sei que nós não somos 'os portugueses', mas somos 'portugueses"' (Coutinho, 2000, p. 36).

Isso não quer dizer que a cumplicidade das elites autóctones com o poder colonial ao longo do tempo autorize afirmar que "a assimetria e a violência [não tenham organizado], desde os primeiros momentos, a presença política portuguesa" em Goa: "a redução da distância entre estes dois grupos" no imaginário imperial e em estruturas do sistema não impediu que "a distância, a diferença e a hierarquia [permanecessem] até ao fim" (XAVier, 2008, p. 449). Daí o ressentimento que pode parecer mover muitas vezes tanto o discurso dos escritores quanto o de muitas das suas personagens, bem como a tentativa de expressão de uma individualidade que ultrapasse os limites de um simples mimetismo colonial?

\section{Referências}

Coelho, José da Silva. O Monserrate. Boletim do Instituto Menezes Bragança, n. 124, p. 158-161, 1979.

Costa, Francisco João da. Jacob e Dulce: scenas da vida indiana. 3. ed. Pangim: Tipografia Sadananda, 1974.

Costa, Orlando da. O último olhar de Manú Miranda. Lisboa: Âncora, 2000.

. O Signo da Ira. 4. ed. Lisboa: Temas da Actualidade, 1996. 
CoutinHo, João da Veiga. Uma espécie de ausência: viver na sombra da história. Versão portuguesa revista pelo autor. Lisboa: Cotovia/Fundação Oriente, 2000.

Couto, Maria Aurora. Goa: história de uma filha. Tradução de Vasco Pimentel. Goa: Fundação Oriente, 2012. In the land of Brahama. In: FigueIRA, Maria Inês; Noronha, Oscar de (Org.). Episódio Oriental: readings in Indo-Portuguese Literature. Pangim: Fundação Oriente/Third Millennium, 2007. p. 88-102.

Dalgado, Sebastião Rodolfo. Glossário luso-asiático. v. 2. Coimbra: Imprensa da Universidade, 1921.

Devi, Vimala. Monção. 2. ed. aumentada. Lisboa: Escritor, 2003. Fernandes, Agostinho. Bodki. Porto: Edição do Autor, 1962.

Loвo, Sandra Ataíde. O desassossego goês: cultura e política em Goa do liberalismo ao Acto Colonial. Tese (Doutorado em História e Teoria das Ideias) - Universidade Nova de Lisboa, Lisboa, 2013.

Machado, Everton V. Introduction. In: Gomes, Francisco Luís. Les Brahmanes. Tradução de L. de Claranges-Lucotte. Edição de Everton V. Machado. Paris: Classiques Garnier, 2012. p. 7-71.

Memmi, Albert. Retrato do colonizado precedido de Retrato do Colonizador. Tradução de Marcelo Jacques de Moraes. Rio de Janeiro: Civilização Brasileira, 2007.

Mendes, António Lopes. A India portugueza: breve descripção das possessões portuguezas na Asia. v. 2. Lisboa: Imprensa Nacional, 1886. 
Ribeiro, Orlando. Goa em 1956: Relatório ao governo. Organização de Suzanne Daveau. Lisboa: Comissão Nacional para as Comemorações dos Descobrimentos Portugueses, 1999.

Rocha, Leopoldo da. Casa Grande e outras recordações de um velho goês. Lisboa: Vega, 2008.

Santos, Boaventura de Sousa. Entre Próspero e Caliban: colonialismo, pós-colonialismo e inter-identidade. In: RAMALHO, Maria Irene; RibeIro, António Sousa (Org.). Entre ser e estar: raízes, percursos e discursos da identidade. Porto: Afrontamento, 2001. p. 23-85.

SARdo, Susana. Guerras de jasmim e mogarim: música, identidade e emoções em Goa. Lisboa: Texto, 2011.

Thomaz, Luís Filipe F. R. De Ceuta a Timor. 2. ed. Lisboa: Difel, 1994.

Xavier, Ângela Barreto. Parecem indianos na cor e na feição:

a "lenda negra" e a indianização dos portugueses. Etnográfica, n.18, v. 1, p. 111-133, 2014. Disponível em: http://etnografica. revues.org/3372. Acesso em: 14 dez. 2014.

. A invenção de Goa: poder imperial e conversões culturais nos séculos XVI e XVII. Lisboa: Imprensa de Ciências Sociais, 2008.

MACHAdo, Everton V. Os paclé (portugueses) em narrativas goesas de língua portuguesa ou o "mimetismo regrado". In: Simas, Monica (Org.). Estudos sobre Macau e outros orientes. São Paulo: Paulistana, 2017. p. 201-223. 